\title{
Anemia and Iron Deficiency in Heart Failure - Clinical Update
}

\author{
András Mester, Adriana Mitre, Erzsébet Lázár, István Benedek Jr, Johanna Kéri, \\ Annamária Pakucs, István Benedek \\ University of Medicine and Pharmacy, Tîrgu Mureș, Romania
}

\section{CORRESPONDENCE}

\section{Adriana Mitre}

Str. Gheorghe Marinescu nr. 38

540139 Tîrgu Mureș, Romania

Tel: +40 265215551

E-mail: adimitre@yahoo.com

\section{ARTICLE HISTORY}

Received: November 2, 2017

Accepted: November 28, 2017
András Mester • Str. Gheorghe Marinescu nr. 38 540139 Tîrgu Mureș, Romania. Tel: +40 265215551 , E-mail: andras.mester@yahoo.com

Erzsébet Lázár • Str. Gheorghe Marinescu nr. 38 540139 Tîrgu Mureș, Romania. Tel: +40 265215551 E-mail: erzsebetlazarbenedek@gmail.com

István Benedek Jr • Str. Gheorghe Marinescu nr. 38, 540139 Tîrgu Mures, Romania. Tel: +40 265215 551, E-mail:benedekistvan73@yahoo.com

Johanna Kéri • Str. Gheorghe Marinescu nr. 38 , 540139 Tîrgu Mures, Romania. Tel: +40 265215551 E-mail: johannakeri@gmail.com

Annamária Pakucs • Str. Gheorghe Marinescu nr. 38 540139 Tîrgu Mures, Romania. Tel: +40 265215 551, E-mail: pakucs.annamaria@gmail.com

István Benedek • Str. Gheorghe Marinescu nr. 38 540139 Tîrgu Mures, Romania. Tel: +40 265215 551, E-mail: istvan.benedek@umftgm.ro

\begin{abstract}
Iron deficiency and anemia affect approximately half of the chronic heart failure patients and they are associated with increased hospitalization rate, lower functional capacity, lower quality of life, and higher mortality. The exact mechanism of iron deficiency in heart failure patients is still not fully understood. Current guidelines recommend ferritin as the most accurate serum biomarker for the diagnosis of iron deficiency. The use of erythropoiesis-stimulating agents is no longer recommended because of the lack of improvement on mortality or hospital readmission rate, and it was associated with a higher rate of thromboembolic events. Intravenous iron replacement therapy is safe and generally well tolerated, with fewer side effects compared to oral administration. Large randomized studies with ferric carboxymaltose demonstrated its effectiveness and superiority to oral administration, and it was associated with a decreased rate of hospitalization rate and worsening heart failure, and improvement of functional capacity and quality of life. Intravenous iron supplementation for chronic heart failure is strongly recommended by European guidelines. Further studies are needed for a better knowledge of this complex pathology and determination of the long-term safety and effectiveness of iron administration in chronic heart failure patients.
\end{abstract}

Keywords: iron deficiency, anemia, heart failure

\section{INTRODUCTION}

Iron deficiency is one of the most frequent nutritional deficits around the world, particularly in developing countries, affecting mostly infants, children, pregnant women, elderly persons, and individuals with chronic conditions such as chronic kidney disease, inflammatory bowel disease, rheumatic and cardiovascular diseases. ${ }^{1,2}$ As an indispensable micronutrient, iron plays and important role in erythropoiesis and protein synthesis, but it is also essential in oxygen storage and transportation and many metabolic processes. ${ }^{3}$ These facts make it indispensable for the proper functioning of the nervous system, thyroid gland, musculoskeletal and cardiovascular system. ${ }^{4}$ Research carried out in the last decade observed a positive correlation between iron deficiency, anemia, and heart failure. Iron deficiency is observed in approximately half of the heart failure 
patients, which further aggravates the quality of life and mortality of these patients. ${ }^{5,6}$ The underlying mechanism is still unknown, but animal models offer a possible answer in form of a link to chronic inflammation in these patients, which leads to absorption deficits. ${ }^{7}$ The first studies that published results regarding iron and erythropoietin administration to treat anemia in heart failure patients concluded that it improved the clinical status (New York Heart Association - NYHA functional class), echocardiographic parameters (left ventricular ejection fraction), and hemoglobin levels of the patients. ${ }^{8}$ Further study results confirmed this theory and proved the efficiency of iron administration for heart failure patients irrespective of anemia. ${ }^{9}$

The aim of this clinical update is to summarize the current knowledge and clinical practice in the management of iron deficiency and anemia in heart failure patients.

\section{IRON METABOLISM}

The human body contains approximately 3-5 grams of iron, which is present in bivalent ferrous and trivalent ferric forms bound to proteins (approximately $75 \%$ to hemoglobin), but it is also present in other organs such as the musculoskeletal system..$^{10}$ It is absorbed via dietary intake at the level of the duodenum and jejunum, and it is mainly stored as ferritin (500-1000 mg) in the hepatocytes, spleen and bone marrow, which should cover the iron demand of up to 36 months in men and 6 months in women due to the regular menstrual cycle. ${ }^{11}$ The iron metabolism is modulated by the liver-derived hepcidin, which inhibits the release of iron from the enterocytes by blocking of ferroportin receptor. ${ }^{12}$ Inflammatory cytokines stimulate hepcidin synthesis resulting in the blockage of iron supplies. Late stages of heart failure are linked with low hepcidin levels, which are associated with worse outcomes. ${ }^{13}$ The exact mechanism of iron deficiency in heart failure patients is still not well elucidated, as different stages of heart failure are linked with variable hepcidin levels.

\section{DIAGNOSIS OF IRON DEFICIENCY AND ANEMIA}

Approximately $30 \%$ of heart failure patients present anemia, which is considered a predictor for mortality and morbidity in these patients, and iron deficiency plays an important role in the development of this condition. ${ }^{14}$ Female sex, advanced NYHA class, N-terminal pro-B natriuretic peptide (NT-proBNP), and C reactive protein (CRP) levels were identified as risk factors for iron deficiency. ${ }^{15}$ The total amount of iron in the body cannot be determined. The most accurate method for the evaluation of iron sta- tus is represented by bone marrow biopsy, but due to its invasiveness it is limitedly used in clinical practice. The most widely used biomarker for the evaluation of the iron status is the determination of ferritin level. However, clinical studies revealed that ferritin can underestimate low iron levels in heart failure patients, as bone marrow biopsies have shown cases of iron deficiency with normal serum ferritin levels. ${ }^{16,17}$ Chronic inflammatory status is also associated with higher ferritin levels; thus, some authors suggest that an index of soluble transferrin receptor (sTfR) and ferritin would define iron deficiency more accurately in heart failure patients. ${ }^{18}$ Current guidelines of the European Society of Cardiology (ESC) recommend (class I, level C) the routine determination of ferritin and transferrin saturation (TSAT) in all heart failure patients. ${ }^{19}$

\section{TREATMENT OPTIONS FOR ANEMIA AND IRON DEFICIENCY}

Early studies that targeted the correction of anemia in heart failure patients and used erythropoiesis-stimulating agents such as erythropoietin and darbepoetin alfa showed promising results in terms of improvement of functional class, left ventricular ejection fraction, and hemoglobin levels. Later studies did not prove the reduction in mortality and hospital admissions and showed a significant increase in thromboembolic events, leading to the removal of these agents from the standard care of anemia in heart failure patients. ${ }^{20,21}$

Iron replacement with iron sucrose without the administration of erythropoietin therapy followed as an alternative for the correction of anemia and iron deficit in chronic heart failure patients. Intravenous iron administration is widely studied, as the first results have led to clinical (NYHA class, exercise capacity), quality of life, and laboratory (hemoglobin level, NT-pro-BNP) improvements. ${ }^{22,23}$ Further double-blind, multi-center studies investigated the long-term (52 weeks) effect and safety of intravenous iron (ferric carboxymaltose) administration. Positive results were recorded in terms of clinical improvement, correction of anemia, and improvement of 6-minute walking distance, with a decreased rate of hospitalization and worsening heart failure..$^{24,25}$ Recent metaanalyses confirmed the safety and efficacy of intravenous iron with reduction of hospitalization rate, but with no significant effect on mortality. Current ongoing trials investigate the clinical outcomes and all-cause mortality with this treatment. ${ }^{26,27}$

Intravenous iron administration is generally well tolerated. The large clinical trials that investigated intravenous 
iron administration in heart failure patients did not report any severe, life-threatening allergic reactions; however, observation of the patients is recommended after iron administration due to minor side effects such as minor allergic reactions, rashes, headache, or nausea. Paravenous administration may lead to long-term skin deposits at the injection site. ${ }^{24,28}$

Oral iron administration represents a therapeutic option for iron replacement in heart failure patients at relatively lower costs compared to intravenous administration. Abnormal absorption due to reduced blood flow of the gastrointestinal mucosa and frequent (more than half of the patients) side effects (e.g., diarrhea, nausea, vomiting, metal taste) significantly reduce the compliance to this administration form compared to the intravenous route. ${ }^{29,30} \mathrm{Few}$ trials compared oral versus intravenous iron supplementation in chronic heart failure patients, but no significant increase of ferritin (as biomarker for iron storage) levels were recorded in patients with oral iron administration, and no changes were detected in peak oxygen consumption for these patients. ${ }^{30}$ Considering the above mentioned results, intravenous iron replacement therapy is preferred to oral administration in chronic heart failure patients.

Current ESC guidelines recommend (class IIa, level A) intravenous iron (ferric carboxymaltose) administration for symptomatic heart failure patients with reduced left ventricular ejection fraction if iron deficiency is identified, irrespective of anemia. ${ }^{7}$

\section{FUTURE PERSPECTIVES}

Ongoing clinical trials investigate the long-term efficiency of intravenous iron replacement therapy in chronic heart failure patients in terms of important end-points such as mortality, worsening heart failure, hospitalization, and quality of life. ${ }^{31,32}$ Research regarding more effective oral iron supplements, with better absorption and fewer side effects is also being carried out in the form of in vitro studies using nanoparticles and early clinical trials, with promising results. ${ }^{33-35}$ The identification of better laboratory biomarkers for detection of iron deficiency is also underway. Many trials suggested that serum ferritin levels may not describe the iron status of heart failure patients accurately due to a chronic inflammatory status in these patients. ${ }^{36,37}$

\section{CONFLICT OF INTEREST}

Nothing to declare.

\section{REFERENCES}

1. Beedkar A, Parikh R, Deshmukh P. Heart Failure and the Iron Deficiency. J Assoc Physicians India. 2017:65:79-80

2. Weiss G, Goodnough LT. Anemia of chronic disease. N Engl J Med. 2005;352:1011-1023.

3. Cairo G, Bernuzzi F, Recalcati S. A precious metal: Iron, an essential nutrient for all cells. Genes Nutr. 2006;1:25-39.

4. Moos T. Brain iron homeostasis. Dan Med Bull. 2002;49;279-301.

5. Klip IT, Comin-Colet J, Voors AA, et al. Iron deficiency in chronic heart failure: an international pooled analysis. Am Heart J. 2013;165:575-582.e3

6. Comín-Colet J, Enjuanes C, González G, et al. Iron deficiency is a key determinant of health-related quality of life in patients with chronic heart failure regardless of anaemia status. Eur J Heart Fail. 2013;15:1164-1172.

7. Ponikowski P, van Veldhuisen DJ, Comin -Colet J, et al. Beneficial effects of long-term intravenous iron therapy with ferric carboxymaltose in patients with symptomatic heart failure and iron deficiency. Eur Heart $J$. 2015; 36:657-668.

8. Silverberg DS, Wexler D, Blum M, et al. The use of subcutaneous erythropoietin and intravenous iron for the treatment of the anemia of severe, resistant congestive heart failure improves cardiac and renal function and functional cardiac class, and markedly reduces hospitalizations. J Am Coll Cardiol. 2000:35:1737-1744.

9. van Veldhuisen DJ, Anker SD, Ponikowski P, et al. Anemia and iron deficiency in heart failure: mechanisms and therapeutic approaches. Nat Rev Cardiol. 2011;8:485-493.

10. Ganz T, Nemeth E. Iron imports. IV. Hepcidin and regulation of body iron metabolism. Am J Physio/ GastrointestLiver Physiol. 2006;290:G199-G203.

11. Jankowska EA, von Haehling S, Anker SD, Macdougall IC, Ponikowski PP. Iron deficiency and heart failure: diagnostic dilemmas and therapeutic perspectives. Eur Heart J. 2013;34:816-829.

12. Schaefer B, Effenberger M, Zoller H. Iron metabolism in transplantation. Transpl Int. 2014:27:1109-1117.

13. Jankowska EA, Malyszko J, Ardehali $\mathrm{H}$, et al. Iron status in patients with chronic heart failure. Eur Heart J. 2013;34:827-834.

14. von Haehling S, Anker MS, Jankowska EA, Ponikowski P, Anker SD. Anemia in chronic heart failure: can we treat? What to treat? Heart Fail Rev. 2012;17:203-210.

15. Jankowska EA, Rozentryt P, Witkowska A, et al. Iron deficiency: an ominous sign in patients with systolic chronic heart failure. Eur Heart J. 2010;31:1872-1880.

16. Brunner-La Rocca HP, Crijns HJ. Iron i.v. in heart failure: ready for implementation? Eur Heart J. 2015;36:645-647.

17. Nanas JN, Matsouka C, Karageorgopoulos D, et al. Etiology of anemia in patients with advanced heart failure. J Am Coll Cardiol. 2006;48:24852489.

18. Gstrein C, Meyer M, Anabitarte P. Iron substitution in the treatment of chronic heart failure. Swiss Med Wkly. 2017;100:w14453.

19. Ponikowski P, Voors AA, Anker SD, et al. 2016 ESC Guidelines for the diagnosis and treatment of acute and chronic heart failure: The Task Force for the diagnosis and treatment of acute and chronic heart failure of the European Society of Cardiology (ESC) Developed with the special contribution of the Heart Failure Association (HFA) of the ESC. Eur Heart J. 2016:18:2129-2200.

20. van der Meer P, Groenveld HF, Januzzi JL Jr, van Veldhuisen DJ. Erythropoietin treatment in patients with chronic heart failure: a metaanalysis. Heart. 2009;95:1309-1314

21. Ponikowski P, Anker SD, Szachniewicz J, et al. Effect of darbepoetin alfa on exercise tolerance in anemic patients with symptomatic chronic heart failure: a randomized, double-blind, placebo-controlled trial. J Am Coll Cardiol. 2007;49:753-762.

22. Bolger AP, Bartlett FR, Penston HS, et al. Intravenous iron alone for the treatment of anemia in patients with chronic heart failure. J Am Coll Cardiol. 2006;48:1225-1227.

23. Toblli JE, Lombrana A, Duarte P, Di Gennaro F. Intravenous iron reduces NT-pro-brain natriuretic peptide in anemic patients with chronic heart failure and renal insufficiency. J Am Coll Cardiol. 2007;50:1657-1665.

24. Anker SD, Comin-Colet J, Filippatos G, et al. Ferric carboxymaltose in patients with heart failure and iron deficiency. $N$ Engl J Med. 2009;361:2436-2448

25. Ponikowski P, van Veldhuisen DJ, Comin-Colet J, et al. Beneficial effects of long-term intravenous iron therapy with ferric carboxymaltose in patients with symptomatic heart failure and iron deficiency. Eur Heart $J$. 2015;36:657-668 
26. Qian C, Wei B, Ding J, Wu H, Wang Y. The Efficacy and Safety of Iron Supplementation in Patients With Heart Failure and Iron Deficiency: A Systematic Review and Meta-analysis. Can J Cardiol. 2016;32:151-159.

27. Jankowska EA, Tkaczyszyn M, Suchocki T, et al. Effects of intravenous iron therapy in iron-deficient patients with systolic heart failure: a meta-analysis of randomized controlled trials. Eur J Heart Fail. 2016;18:786-795.

28. Miller HJ, Hu J, Valentine JK. Gable PS. Efficacy and tolerability of intravenous ferric gluconate in the treatment of iron deficiency anemia in patients without kidney disease. Arch Intern Med. 2007:167:1327-1328.

29. McDonagh T, Macdougall IC. Iron therapy for the treatment of iron deficiency in chronic heart failure: intravenous or oral? Eur J Heart Fail. 2015;17:248-262.

30. Lewis GD, Malhotra R, Hernandez AF, et al. Effect of oral iron repletion on exercise capacity in patients with heart failure with reduced ejection fraction and iron deficiency: the IRONOUT HF Randomized Clinical Trial. JAMA 2017:317:1958-1966.

31. Beck-da-Silva L, Piardi D, Soder S, et al. IRON-HF study: a randomized trial to assess the effects of iron in heart failure patients with anemia. Int $J$ Cardiol. 2013:168:3439-3442
32. Effectiveness of Intravenous Iron Treatment vs Standard Care in Patients With Heart Failure and Iron Deficiency: a Randomised, Open-label Multicentre Trial (IRONMAN) Available at: https://clinicaltrials.gov/ct2/ show/NCT02642562

33. Pereira DI, Mergler BI, Faria N, et al. Caco-2 cell acquisition of dietary iron(III) invokes a nanoparticulate endocytic pathway. PLoS One. 2013;8:e81250.

34. Pisani A, Riccio E, Sabbatini M, et al. Effect of oral liposomal iron versus intravenous iron for treatment of iron deficiency anaemia in CKD patients: a randomized trial. Nephrol Dial Transplant. 2015;30:645-652.

35. Latunde-Dada GO, Pereira DI, Tempest B, et al. A nanoparticulate ferritincore mimetic is well taken up by HuTu 80 duodenal cells and its absorption in mice is regulated by body iron. J Nutr. 2014;144:1896-1902.

36. Cleland JG, Zhang J, Pellicori P, et al. Prevalence and outcomes of anemia and haematinic deficiencies in patients with chronic heart failure. JAMA Cardiol. 2016;1:539-547.

37. Nemeth E, Rivera S, Gabayan V, et al. IL-6 mediates hypoferremia of inflammation by inducing the synthesis of the iron regulatory hormone hepcidin. J Clin Invest. 2004;113:1271-1276. 